Interdisciplinary Research in Education

Volume 4, Issue 2, 2019: 162-172

DOI: https://doi.org/10.3126/ire.v4i2.27930

\title{
Fostering Learner Autonomy by using Moodle as Pedagogical Tool: Reflections on Students' Perceptions
}

\author{
Arjun Neupane \\ Central Department of Education \\ Tribhuvan University \\ Kirtipur, Kathmandu, Nepal \\ arjun.neupane@tucded.edu.np
}

\begin{abstract}
Moodle is an open source for e-learning system. It is as a tool for delivering contents to students and it is useful to build rich collaborative learning communities. It allows users to be active learners, who actively participate in the online learning process. Based on this background, this study aimed to investigate the students'views on the use of Moodle in mathematics education. This study gave attention to the variables of perceived usefulness, perceived ease of use, attitude and students' self-efficacy in learning mathematics. Participants of this study consisted of 24 students, who took first and second semester courses at the master's level in Mathematics Education in 2018 batch from Open and Distance Education Center (ODEC), TU. There are 21 male and three female students. Four students were chosen for interview including one female representative. Data triangulation between the data of interview, online observation and interview with online teachers were used to analyze and analysis of the data. Three online teachers were chosen for interview purposively. The finding revealed that students had positive perception towards the use of Moodle and were happy to learn mathematics from the online mode rather than face-to-face mode. It is suggested that the Moodle, if used appropriately and systematically, benefits tutors and students equally.
\end{abstract}

Keywords: Computer collaboration, Moodle, learner autonomy, open and distance learning

\section{Introduction}

The development of technology has changed traditional classroom-based teaching, as the normal mode of instruction, in many ways. Technology enhancement has been seen as an innovative new approach to teaching (Benson \& Voller, 1997; Benson, 2006). Technology enhancing has been linked to learner autonomy because of the possibility to enhance both any time learning and distance learning.

A course management system (CMS) is an integrated software system that incorporates internet and web technologies to support and enhance education programmes. They are becoming increasingly common throughout higher education (Papastergiou, 2006). 'Virtual 
Fostering Learner Autonomy by using Moodle as Pedagogical Tool: Reflections .../ 163

learning environment (VLE), web learning environment (WLE), managed learning environment (MLE) and networked learning environment (NLE)' are terms also used as alternatives to CMS (Navaporn, 2010, p. 111). Moodle or modular object-oriented dynamic learning environment (Moodle) is a widely used open source CMS designed by Martin Dougiamas. Moodle was designed to support a social constructivist approach to teaching and learning which includes inquiry-based, collaborative interaction and construction of shared knowledge (Brandl, 2005). Moodle platform is very useful for online learning in mathematics education.

The Internet-based technologies and World Wide Web are the foundations of open and distance learning environment. It has become increasingly important in the field of education and provide more choice and flexibility in teaching and learning. According to Boldt, Gustafon and Johnson (1995), internet is an excellent learning tool to enrich students' learning and experiences. E-learning, which is described as the use of ICT to enhance and support the teaching and learning in education has become increasingly important in tertiary education (OECD, 2005). New technological tools enhance and support to the online students for the development of learners autonomy.

According to Sanchez and Hueros (2010), E-learning is now a fundamental tool for universities and educational institutions to gain a competitive edge. E-learning allows students not to be in the classroom and therefore gives them more flexibility to learn and interact with other students and lecturers. However, the success of e-learning is dependent on students' acceptance and usage (Sanchez \& Hueros, 2010). In recent years a shift has occurred in higher education, the role of university is no longer as a provider of knowledge, but instead to create an environment that the students can explore, discover and learn by them.

\section{Moodle as a Pedagogical Tool}

Technology should be used as a tool and provide a platform for achieving objectives and standards (Reigluth, 1999). Web-based courses management system is the latest pedagogical tool based on technology (Wernet, Olliges \& Delicath, 2000). Web-based Course Management Systems (CMS) are an increasingly important part of academic systems in higher education. There is several learning management system (LMS) commercially available on the market such as Blackboard, WebCT and Desire@Learn. There are also many open-source, free LMS, such as Moodle, Coursework, Atutor and Interact. However, Moodle is one of the popular LMS currently (Suleiman, Umar \& Abdu, 2012, Chewe \& Chitumbo, 2012). In addition, moodle was further chosen due to its social-constructivist nature (Moodle, 2010).

Moodle is a course management system which enables delivery of online education. Moodle allows instructors to plan and designate activities for the students. It is a dream tool for teachers, integrating wide range of resources and assessment strategies and is powerful in content creation (Ahmed \& Raheem, 2012). As stated by Ayse (2008), it is unwise to ignore the pedagogical impact of moodle.

The underlying philosophy of Moodle is maximum instructor control and minimal administrator control (Moodle, 2010). Moodle is based on the philosophy of socio- constructivist 
pedagogy which encourage discovery and provide collaborative activities. It is seen as users friendly and easy to manage and technically easy. It adapts a flexible modular design and one can choose and apply among thousands of available extensions for their version of Moodle (Unal \& Unal, 2011). Moodle helps to promote conceptualize the mathematical concepts and reducing the abstractness of the subject matter of mathematics.

Open and distance learning (ODL) has recently become a trend in most institutions of higher learning particularly in developing countries (Slagter, Tryon \& Bishop, 2009) such as Nepal. This occurs because many developing countries are beginning to realize that it could be an effective way of increasing access to university or education in general. More and more university higher subjects such as mathematics are being offered using open, flexible, distance and online approaches. However, one of the fundamental barriers to the spread of open and distance learning is to ensure that instructors are able and competent enough to deliver better quality instruction and set up meaningful educational experiences for the learners. This concern arises because of the unique nature of the open and distance mode in mathematics education. Hence, this study sought to investigate teachers' experiences with open and distance teaching at masters' level of mathematics education in Tribhuvan University (TU), Nepal.

Understanding of the needs of open and distance mode in mathematics education in TU feels and started from 2015 by Open and Distance Education Centre (ODEC), as a different constituent campus of TU. Masters' degree in Mathematics Education (M.Ed.) program has runs thoroughly from that date in semester system. This practice is new in Nepal. No one has believed to run MEd in mathematics with open and distance mode so smoothly. In this short period of time, the charming of students increases in the geometrical ratio at ODEC.

\section{Literature Review}

Constructivism is a broad theoretical perspective which includes different types of constructivism and many divergent theories. Heinecke, Dawson and Willis (2001 cited in Papastergiou, 2006, p. 594) describe nine areas where constructivist instructional principles lie: 'negotiation of learning objectives; student control over their learning; authentic, purposeful and contextual learning; problem solving; collaborative learning; multiple, alternative perspectives; knowledge construction and validation through action and discourse; authentic assessment; and development of metacognitive skills'.

Moodle was developed as the online platform of social constructivism philosophical base. Ding (2012) stated that constructivist epistemology is core to a wide range of autonomy definitions particularly Little's psychological perspective of autonomy and also Holec's (1981, p. 21, as cited in Ding, 2012) view of autonomy where the learner 'constructs and dominates' his own version of knowledge.

Moodle was developed based on these constructivist principles with a focus on social constructivism which regards learning as a social activity. Social constructivism places the learner, as an active member, at the centre of the learning process and highlights the importance 
of social and co-operative learning with the construction of personal knowledge (Brandl, 2007; Brown, 2007; Papastergiou, 2006; Tam, 2000).

For Smith (2008), Vygotsky pioneered research into social constructivism with his concept of the zone of proximal development. His concept of scaffolding learning with the help of an experienced other places the responsibility of the teacher to facilitate a collaborative problemsolving environment and guide students with expert help (Tam, 2000). In this study, I use Moodle as a tool to scaffold the development and construction of meaning through the sharing of ideas, texts and other sources. This approach mirrors the process of knowledge creation in academia in which learners are apprentices in a community of practice, and knowledge is socially constructed and constantly evolving (Angelo, 2000 cited in Papastergiou, 2006; Dougiamas \& Taylor, 200; Warschauer, 2005).

Moodle may provide a context for learners to apply and develop autonomy. Users are able to control the pace of learning, mode of interaction, and by enhancing opportunities for collaborative learning, control of interaction (Blin, 2004; \& Benson 2001). This responsibility for learners to take control of their learning may also empower and motivate learners which may foster autonomy (Murry, 2005; \& Schwienhorst, 2003). However, the exercise and development of autonomy through the use of Moodle may require learners to already be autonomous to a certain degree, as they have to navigate and use this new technology effectively (Benson, 2001). Smith (2001, p.396) states this 'form of learning may require the exercise of autonomy, but they do not necessarily develop this capacity'.

The use of Moodle may require users to be digitally literate and possess digital competency skills so they are able to navigate and use Moodle effectively (Ryberg \& Georgsen, 2010, p. 89). This needs to be a consideration for the EAP practitioner when using Moodle on how digital literacies can be taught or enacted, and includes the recognition of multiple literacies and how they are created as a social practice (Street, 2003; Ryberg \& Georgsen, 2010). Finally, Moodle can be used in a variety of different ways and how it is used is important to what extent it can foster autonomy. The final part of the essay will discuss how I facilitate learner autonomy with the use of Moodle and discuss what advantages and limitations it has.

\section{Methodology}

In this study, I used phenomenological research method as a type of qualitative approach (Creswell, 2014). I used as a research instruments for collecting data from interviewing participants, observing their behaviors and examining relevant documents that relate to the phenomenon under study. I used the responses of students to verify the data given by teachers. I triangulated my data to make the results valid. Methodological triangulation of my study indicates the efficiency and sufficiency of methods.

\section{Context and Participants}

Participants of this study consisted of 22 students, who admitted to ODEC for the first semester courses at the master's levels in mathematics education in 2017. There were 19 male and three female students. The active involvement and effective interaction between students 
and student and teacher were the components of this course. Course synopsis, content material, assignments, forums, web resources and tutorials could be found online. Students could download content material, send assignments, and interact through forum with instructors or friends. The context of this study was a masters' level course, the history of mathematics at O D E C, Tribhuvan University, Nepal.

\section{Research Scenery}

At the early of semester, the researchers gave briefing regarding the components of Moodle and its functions. This briefing takes about two hours. The researchers demonstrate on the use of Moodle to the students so that they clearly understand about how to use it. I also notify students that the use of it a part of the course evaluation. Other than participating in presentation and forum students also need to get material (like syllabus, notes, and lecture), send assignments, and interact with instructors or with other partners. I also make announcement through Moodle. I was observing all the activities of the students. I interviewed with teachers for the validation of the data and research procedure. My focus of the study was the students' fostering through the use of Moodle and increasing the students' autonomy.

\section{Findings}

Thematic analysis was used to analyze the data. Data triangulation was used to make validity of the findings. Theoretical literature helps to make the themes of the study. The findings of this study have been presented with the help of the following themes.

\section{Practice for Learner Autonomy}

The term autonomy has become prominent over the past thirty years with the shift in theory and teaching praxis of second language acquisition towards learner centered approaches. There are no clear simplistic definitions of autonomy due to its social, psychological, political and pedagogical aspects (Benson \& Voller, 1997; Reinders \& Balcikanli, 2011). However, Ding (2012) argues that by trying to create a single version of or defending the original definitions of autonomy we limit the possibility of developing theory and classroom practice.

In my current context, students have already shown a psychological capacity and proactive autonomy by continuing study 'in a world which they themselves have partially created'. As a practitioner, I may develop reactive autonomy by facilitating situations where learners can learn autonomously and 'organize their resources autonomously to reach their goals' (Littlewood, 1999, p.75). The learners' autonomy helped to promote and raising their potentialities in online learning.

According to Voller (1997, p. 102) teachers develop these three specific roles and qualities: a facilitator, teachers should help scaffold and organize autonomous learning by understanding their students' needs and setting achievable goals; a counselor, by offering support, motivating students and transitioning the shift in student-teacher roles; and a resource, by directing and advising on strategies and resources in and out of the classroom. Based on the above definitions, I have taken the learning platform; Moodle that learner and teacher autonomy are interrelated to each other. In this study, I have taken Moodle as a tool combined with relevant pedagogy to 
Fostering Learner Autonomy by using Moodle as Pedagogical Tool: Reflections ... 167

promote autonomy for online mathematics education. Students feel enjoyable and happy to learn mathematics through the open and distance mode. For example, student said,

Open and distance learning in very useful and interesting to develop the professionalism holding our job. This is a good and new trend and effective for the job holders like us.

Getting Job is very difficult in Nepal. Self-employment is more difficult in these days. To address the need of students, ODEC supports them for the development of new and skilled mathematics educators. These types of human resources increase the need and importance of mathematics education. These types of pedagogy empower the learners' autonomy.

I can serve the internet at the leisure time for study. It will help to avoiding the scheduled time and fixed learning. Any interesting mathematical contents can learn freely. No time bound is the beauty of this mode. (S2)

Office hour is not necessary to learn mathematics at higher level. Students can make their meaning freely. Therefore, students are very happy with the distance mode of instruction. These types of pedagogy increase the learner autonomy.

I can recall the past contents as well. Additional information can be found in the online learning. I am feeling as a new experience. We are totally guiding with the thinking from face to face mode of teaching. It is strange and student-centered autonomous pedagogy. (S3)

Repetition is necessary for mathematics learning at higher level. Moodle platform provides the repetition if necessary. Learner's autonomy is the beauty of online and flexible learning in mathematics education in Nepal.

\section{Digital Competency Skills}

The integration of digital technology confronts teachers, educators and researchers with many questions. What is the potential of ICT for learning and teaching, and which factors are decisive in making it work in the mathematics classroom? The crucial factors for the success of digital technology in mathematics education include the design of the digital tool and corresponding tasks exploiting the tool's pedagogical potential, the role of the teacher and the educational context.

First, I am unknown about the online system. -After the first contact session provided by ODEC, I am able to operate Moodle thoroughly. I use e-mail, Facebook, and phone other than Moodle for mathematics learning. (S2)

Open and distance mathematics education helps to foster students' competency and fulfill the need of the teachers of twenty first century. Not only Moodle but also the other digital tools can use to make online education more interactive and effective. Digital technology reduces the 
difficulty level of a discipline. Difficult contents of mathematics can teach or learn differently. It opens the door of multiple idea of mathematical solution in formal education informally.

\section{Assessment and Engagement}

All students were afraid of the assessment and examination. Moodle helps to make conditioning about assessment. It promotes all-round development of the students. Students feels about the continue process of evaluation.

I am very afraid of exam, but in this system, I am happy with the final exam. (S1)

Students were very interested and enjoy with the use of quiz and figurative expressions that I use in my mathematics courses. I have used self-evaluation tests in the contact session. Questions had given by themselves, and evaluate their copy by themselves. It was first use to assessment evaluation techniques. Students felt more autonomous to assessment and they got the knowledge about the style of writing and deepness of their writing.

I feel, Self-assessment and evaluation technique is very interesting and effective. Internal assessment examination is more beneficial for the formation of the final exam and a new experience. (S3)

Students must appear for online learning. The outcomes of online learning depend upon the level of engagement of the students. Moodle was a new learning management system for the students. Thus they feel difficult at first, and then they feel easy to read and write.

First, I am unknown, after first contact session we are trying to playing and enjoying with moodle, at last, I have no enough time for practice. (S2)

Online observation indicate that only $20 \%$ students were involved regularly. They are busy and involved to conducct their others work. Althoutht, they are very interested to learn throught moodle.

\section{Resources and Collaboration}

Resources are the means for fostering students learning capacity and increasing their autonomy. Moodle is a suitable learning environment that promotes the students' autonomy. Students feel open to learning and teacher has teaching freely. Let us see some students' reflections.

I found different additional resources in Moodle. It will be more beneficial for us.(S4)

Up to first contact session, we are not familiar with each other, but we share our ideas after the period. (S2)

Very little practice of video conferencing and interaction between the students because we all are busy in job. (S3) 
Students' collaboration was a beauty of Moodle environment. But our students were not so practice and sufficient skills for smooth operation. First of all, they were just opened and play to learn Moodle rather than efficient use of it for online learning. After the first contact session, they were started to collaborate some mathematical ideas and sharing the information. They all are busy in their job. They have only off hours' time for reading. They were used their knowledge and attempt for learning mathematics carefully. But, from my observation given in table 1, 50 percentages of the students were passive to operate Moodle and learning mathematics. They leave their classes as well because of their tile limitations.

\section{Practice of Learner Autonomy}

Moodle facilitates students' autonomy for learning and teaching mathematics. It is just a means for learning. Students use the contents, discussion forum, blue button, group SMS and other for their collaboration their ideas. At the time of study, I use video conferencing very little. But the students' expectations were a bit more at the time of interview. Let us see the statements of students.

One-week orientation is necessary for the initial semester for familiar between the students. (S1)

It will better if we can see the teaching video in Moodle or online tutorial. (S4)

It will better if the presentation by student is compulsory at the time of contact session for a particular topic for each of the students. We study more for the presentation. This will help us for the final exam and it will increase the potentiality of the students. (S3)

ODEC provides only three days orientations for beginning of the semester. Students' reflections indicated that it was necessary to extend up to one week. They focused about the teaching video for reading and justification of the proof. This helped to read and reduced to language problem. Pupils added towards a talk or presentation about a topic. This increases their potentiality and empowering to them. These types of activities promote to the pupils' autonomy.

Key notes for each unit are very important in online learning. (S1)

Video conferencing is important for reading and the development of cognitive structure to the students. (S3)

I have language problem to understand the question and writing the solution. Internal assessment provided us about the model questions and the nature of questions for final exam. (S4)

I feel very difficult having female students to managing time for home and school. (S2) 
Students like to read easily as soon as possible. The key points and short notes were demanded by them for online learning. Video conferencing helped to increases our autonomy to learn at any time and any way. Gender bias is one of the serious problems in the Nepali society. She has to involve in almost every household work and at office as well. Time management is a bit difficult for female students. Assessment written examination was held at the time of contact session. It was very beneficial to the students for final preparation and practice.

\section{Discussion and Educational Implication}

On the whole, students have a positive view towards Moodle. This is in line with the studies by Hanafi, 2004) and Paris (2004) which states that students have a positive attitude towards online learning. Further, in a study by Zoran \& Rozman (2010), their respondents commented that Moodle was helpful, useful, time-saving, and above all that it had a positive influence on their learning. Drennean, Kennedy and Pisarski (2005) reported that a high positive perceptions, is related to high satisfaction towards online learning. Melton (2006) highlighted the usability of Moodle which may contribute to the positive perceptions. Students who have a positive attitude towards e-learning will easily accepted e-learning (Research Institute of Bangkok University, 2002).Students feel easy to learn using online mode if they were practiced on Moodle.

Moodle, if it's used appropriately and systematically, it will benefit lecturer and students accordingly. Students' experiences in using Moodle will initiate them to fully utilize its potential in their teaching career. It has shown that teaching using web-based system can be used as one method of delivery for Master of Education course. Integrated features within Moodle facilitate students in the classroom to upload their assignment other than participating in forum actively. Apart from that, Moodle enable teacher to interact with students with more effective. However, effort to make implementation a success require instructors be trained, have good network facility and access to technology, technical and administrative support.

\section{Conclusion}

This study gives preliminary data about students' reflections towards Moodle. On the whole, perception of graduate students towards Moodle is very positive. As a result of this study we can conclude that Moodle can be used as a tool for the teaching of graduate courses in mathematics education. This will promote the students' autonomy and increases the importance of mathematics in the computer age. The open and flexible learning will includes the students who left their classes because of their scarcity and necessary to holding job within country or out of country. But the facilities of credit transfer between both face to face mode and open and distance mode is necessary. The unavailability of network facilities, time management of students, inefficient use of online pedagogy, lack of incentives were the major problems and challenges for the future for open and distance teaching learning and for the ODEC as well. 
Fostering Learner Autonomy by using Moodle as Pedagogical Tool: Reflections ... 171

\section{References}

Ahmed, Y. \& Raheem, A. (2012). Interactions quality in Moodle as perceived by learners and its relation with some variables. Turkish Online Journal of Distance Education, $13(3), 375-389$.

Angulo, A. J. \& Bruce, M. (1999). Students perceptions of supplemental web-based instruction. Innovative Higher Education, 24 (2), 105-125.

Ayse, K. (2008). An online social constructivist tool: A secondary school experience in the developing world. Turkish Online Journal of Distance Education, 9 (3), 87-98.

Benson, P. (2000). Autonomy as a learners' and teachers' right. In Sinclair, B., McGrath, I. and Lamb, T. (Eds.) Learner autonomy, teacher autonomy: Future directions. pp. 111-117. London: Longman.

Benson, P. (2006). Autonomy in language teaching and learning. Language Teaching 40: pp. 21-40.

Benson, P. and Voller, P. (1997). Introduction. In: Benson, P. and Voller, P. (Eds.) Autonomy and Independence in Language Learning, pp. 1-12. London: Longman.

Chewe, P. \& Chitumbo, E. M. M. (2012). Moodle adoption at the University of Zambia: Opportunities and Challenges, Science Journal of Sociology and Anthropology, 2012, doi:10.7237/sjsa/289

Ding, A. (2012) Deconstructing and Reconstructing Teacher Autonomy: A Case Study of Teacher-Learners' Autonomy on a TESOL MA. Ph.D. thesis, University of Nottingham.

Dougiamas, M. and Taylor, P. C. (2003). Moodle: Using Learning Communities to Create an Open Source Course Management System. EDMEDIA: Honolulu.

Grob, A. and Wolff, D. (2001). A Multimedia Tool to Develop Learner Autonomy. Computer Assisted Language Learning 14(3-4): pp. 233-249.

Hanafi, A., Zuraidah, A., Rahman-dan R. \& Idrus, M. (2004). Characteristics of the Web-Based Learning Environment in Distance Education: Students' Perceptions of Their Learning Needs. Educational Media International, 41(2), 103-110. Retrieved from http://www. tandf.co.uk/journals

Melton, J. (2006). The LMS Moodle: A usability evaluation. Languages Issues.

Moodle (2010). Moodle Website. Retrived from, http://moodle.org

Naqvi, S. (2006). Impact of WEbCT on Learning: An Oman Experience.

Navaporn, S. (2010). The application of a course management system to enhance autonomy in learning English as a foreign language. System 38: pp. 109-123.

Papastergiou, M. (2006). Course Management Systems at Tools for the Creation of Online Learning Environments: Evaluation from a Social Constructivist Perspective and Implications for their Design. International Journal on E-Learning 5 (4): pp. 593-622. 
Reigluth, C. M. (1999). Instructional design theories and models: A new paradigm of instructional theory, Lawrence Erlbaum Associates.

Reinders, H. and Balcikanli, C. (2011). Learning to Foster Autonomy: The Role of Teacher Education Materials. Studies in Self Access Learning Journal 2(1): pp. 15-25.

Ryberg, T. and Georgsen, M. (2010). Enabling digital literacy: Development of Meso-level Pedagogical Approaches. Nordic Journal of Digital Literacy [online]. 5 (2): 88-100. Available at $<\mathrm{http}: / / w w w . i d u n n . n o / t s / d k / 2010 / 02 /$ art03> [Accessed 26 October 2013].

Sanchez, R. A. \& Hueros, A. D. (2010). Motivational factors that influence the acceptance of Moodle using TAM. Computers in Human Behavior, 26, 1632-1640.

Santamaria, J. S., Ramos, F. J. \& Antolin, P. S. (2012). The student's perspective: Teaching usages of MOODLE at University. Proceedings of ICERI 2012 Conference, Madrid, Spain. 19-21 Nov 2012.

Smith, R. (2008). Learner autonomy. ELT Journal 62 (4): pp.95-397.

Tam, M. (2000). Constructivism, Instructional Design, and Technology: Implications for Transforming Distance Learnisng. Educational Teachnology \& Society 3 (2). Available at $<$ http://www.ifets.info/journals/3_2/tam.html $>$ Accessed $25^{\text {th }}$ October 2013.

Voller, P. (1997) Does the teacher have a role in autonomous learning? In: Benson, P. and Voller, P. (Eds) Autonomy and Independence in Language Learning, pp. 98-113. London: Longman.

Warschauer, M. (2005). Sociocultural perspectives on CALL. In: Egbert, J. and Petrie, G. M. (Eds.) CALL Research Perspectives, pp. 41-51. New Jersey: Lawrence Earlbaum. 